\title{
ENTRE LA MALDICIÓN Y EL CANON: MECANISMOS DES-INSTITUYENTES EN LA ESFINGE DEL SENDERO
}

\author{
Carlos Manuel Villalobos
}

\begin{abstract}
RESUMEN
Este artículo analiza el financiamiento de los mecanismos des-instituyentes (estrategias de descatalogación textual) en el ámbito literario a partir del texto La esfinge del sendero, de Jenaro Cardona. Se parte del hecho e que la descatalogación de este texto responde a razones extraliterarias, relacionadas con moral y religión.

Palabras clave: La esfinge del sendero, Jenaro Cardona, mecanismos des-instituyentes.
\end{abstract}

\begin{abstract}
This article analyzes the funding of the deinstituent practices (strategies of textual decatalogation) in the literary scope from the lext La esfinge del Sendero by Jenaro Cardona.

The article points out that tha decatalogation of this text is due to extraliteraty reasons related to morality and religion.

Key words: La esfinge del Sendero, Jenaro Cardona, deinstituent practices.
\end{abstract}

En 1916, cuando Argentina se preparaba para conmemorar el primer centenario de su independencia, El Ateneo de Buenos Aires convocó a un concurso interamericano de novela. Un joven escritor costarricense sometió a consideración del jurado una novela que tituló La esfinge del sendero. A juicio del connotado crítico Estanislao S. Zeballos, esa novela debió haber ganado el primer lugar, pero el jurado había decidido otorgarle el segundo premio, a pesar de que uno

M.L. Carlos Manuel Villalobos. Profesor de la Escuela de Filología y Lingüística de la Universidad de Costa Rica. San Pedro, San José, Costa Rica.

Correo electrónico: cmvillal@racsa.co.cr

Recepción: 09-02-2005

Aceptación: 10-03-2005 
de los miembros se había opuesto enérgicamente a que se le diera tal distinción. Los señores Dr. Cantón, Dr. Agote y Dr. Peña dieron un veredicto favorable y, como mayoría, lograron que el texto recibiera la condecoración de plata ${ }^{1}$. ¿Qué propició esta diferencia de opiniones polarizadas? ¿Por qué la prensa argentina desató en ese momento una polémica que terminó sepultando, no solo en este país suramericano, sino incluso en Costa Rica, una novela que parecía estar destinada a ocupar un espacio en los archivos del canon? Hoy esta novela no circula, no figura en las páginas de la historia: es solo un dato de nacimiento y muerte que de vez en cuando alguien mira cuando recorre la tumbas de algún cementerio bibliográfico.

Exhumar los restos de este texto podría verse como un intento de resurrección milagrosa y, en consecuencia, de sacralización. Pero no es ese el objetivo de este ensayo. Más bien pretendo reflexionar sobre el funcionamiento de los mecanismos des-intituyentes en el campo literario, o más precisamente, como lo propuso Pierre Bourdieu, las estrategias de la descatalogación textual. Parto de la hipótesis de que La esfinge del sendero fue descatalogada no por la sospecha estética ni por la caducidad del imaginario modernista como formación discursiva de base, sino por razones eminentemente extraliterarias: Jenaro Cardona cuestionó directamente los emblemas religiosos de las doxas morales latinoamericanas. Cavar la tumba del discurso hereje, a través de la censura editorial, permitió entonces vencer el peligro que implicaba el proyecto cardoniano.

La publicación hecha en Argentina en 1916 salió sumamente defectuosa y prácticamente no circuló a pesar de que fue objeto de discusión en varios artículos periodísticos. En 1925, el autor intenta hacer una segunda edición en Costa Rica. Hace las correcciones y prepara un prólogo explicativo. Sin embargo, una serie de excusas editoriales terminó por impedir que la novela se publicara. Cardona nunca encontró apoyo y su muerte, en 1930, le impidió ver esta segunda edición impresa.

En 1970, la Editorial Costa Rica acuerda por fin publicarla, pero es entonces la familia Cardona, radicada ahora en México, la que se niega aduciendo razones afectivas, dada la censura que habían sufrido a causa del texto. El escritor Alberto Cañas viaja a México y consigue furtivamente ${ }^{2}$, el ejemplar que había corregido Cardona en 1925.

La caducidad de los derechos de autor, según las leyes costarricenses, le impidió a la familia evitar el tiraje. La edición constó de tres mil ejemplares y de este modo parecía hacerse justicia. Pero la novela nunca ha formado parte de los programas de educación en Costa Rica y, aunque se reeditó posteriormente, no se consigue en ninguna librería, excepto de vez en cuando en una tienda de libros usados, posiblemente desechada urgentemente por algún lector horrorizado.

La construcción del canon literario no solo la determinan los verosímiles estéticos de una época, sino también otras representaciones culturales que actúan al margen de la obra y posibilitan las condiciones de circulación y consumo. Las valoraciones estéticas no son los únicos instituyentes que propician los procesos de legitimación de ciertos autores y ciertas obras. Según Bourdieu, las estrategias de los agentes y de las instituciones que están comprometidos con las luchas literarias o artísticas no se definen en la confrontación pura, sino que dependen de la posición que ocupen en la estructura del campo, "es decir en la estructura de la distribución del capital específico, del reconocimiento, institucionalizado o no, que les es concedido por sus pares-competidores o por el gran público" (1995: 309). Es evidente que en el caso de Jenaro Cardona, no fueron suficientes los códigos discursivos del verosímil estético. La novela no pudo superar las objeciones aparte que lanzaron los agentes distributivos y las instituciones moralizantes. 
Siguiendo un modelo pragmático-enunciativo, es posible distinguir cuatro entidades comunicativas básicas: los productores, los intermediarios, las audiencias y los instituyentes. Estos agentes deben operar en conjunto para asegurar la legitimación del texto. De ellos depende que la llama sagrada de una obra se mantenga encendida o se apague. Si uno de los agentes falla, el ciclo de la producción, distribución, consumición e institución anula las posibilidades de permanencia. Todo campo discursivo mantiene una lucha donde hay textos emergentes o discrepantes que intentan desestabilizar la autonomía y la certeza de lo institucional. Pero la contraparte pone en el juego vigilantes que intervienen en el ciclo comunicativo y son precisamente los encargados de anular la vigencia de la obra interdicta.

A continuación, analizaré el ciclo enunciativo de La Esfinge del Sendero, para intentar establecer qué mecanismos descatalogadores operaron en este caso.

\section{Producción y distribución}

Según Michel Foucault, el autor caracteriza un cierto modo de ser del discurso (1999: 338). Pero también, el enunciatario o los enunciatarios de la obra se muestran a sí mismos y muestran la formación discursiva, simbólica e ideológica desde la que producen. En algunos contextos, la presencia de este primer agente productivo puede ser tan significativa que el nombre mismo es capaz de sostener la trascendencia del texto. Pero esta fetichización de la firma autorial evidentemente no se produce en el caso de Jenaro Cardona (1863-1930). Aunque tuvo una vida pública activa: fue congresista, cónsul, periodista, miembro de la Academia Española de la Lengua, como escritor tropezó con la voluntad del poder eclesiástico. A la edad de tan solo 19 años, por integrar un grupo de lectores que leía libros prohibidos, fue excomulgado por la Iglesia Católica ${ }^{3}$. Durante su vida, fue miembro activo de la masonería costarricense (Bowden y Obregón 1940: 21) y como político se adscribió a las propuestas liberales de la secularización del Estado.

La obra literaria de Cardona fue relativamente corta. Se limita a un escaso número de poemas que aún no han sido publicados en forma de libro. Algunos aparecieron en Lira costarricense, la primera antología de poetas costarricenses que se publicó en 1890. Publicó dos novelas: El primo (1905) y la ya mencionada La esfinge del sendero (1916). En 1929 publica también un libro en el que recoge sus cuentos y que titula: Del calor hogareño. Por otra parte, en los periódicos que circularon a principio del siglo aparece un sinnúmero de artículos periodísticos que solía publicar bajo el seudónimo de "Caro de Aragón”. En 1930 preparaba una novela de costumbres que había titulado Retablo político, pero la muerte le impidió concluirla.

En la novela El primo, el sistema patriarcal que formaba parte de la base social de la familia costarricense entra en crisis. Mario Astoga se avergüenza de sus padres y se convierte en un vividor. El primo, Beltrán Urdaneta, que es recibido con honores por ser rico, termina embarazando a su prima Matilde y huye cobardemente del país. En los cuentos, estas representaciones de decadencia continúan latentes. En el cuento "Las dos amigas", el tema de la infidelidad articula el relato y en el cuento "Edith", la desintegración familiar reaparece cuando la mulata limonense Edith es abandonada por su esposo Henrik, de origen alemán.

Sin embargo, el texto que más cuestiona la lógica del sistema moral es La esfinge del sendero. La novela presenta el conflicto del celibato y muestra con una serie de ejemplos el sinsentido de este dogma católico. 
El protagonista es Rafael María, un joven que aspira a ser sacerdote, pero en el proceso se enamora de Engracia y finalmente desiste. Los diversos sacerdotes que aparecen en la narración tienen historias de amor que los colocan en la disyuntiva de la tentación y la abstinencia. El virtuoso sacerdote y zapatero Juan, por ejemplo, había abandonado a su novia y se metió al seminario solo para satisfacer a sus padres. Pero el más polémico, y quizá lo que transforma esta novela en un texto iconoclasta, es la biografía del padre Félix, cura de un pueblo llamado El Piñal. El sacerdote se aprovecha de los diezmos y se enriquece, mientras abusa sexualmente de varias muchachas del pueblo. Incluso, a vista y paciencia de los lugareños, llega a procrear hijos en la casa cural. Finalmente, comete incesto con su hija adolescente. Para expiar las culpas, el sacerdote recurre a la Biblia y encuentra respuestas que lo tranquilizan. Lee una y otra vez el Cantar de los Cantares y le reconforta el contenido erótico. También, en uno de sus delirios libidinosos, encuentra, en el pasaje de Lot y sus hijas emborrachándolo, una justificación para los encuentros carnales con su propia hija.

Luego de uno de sus encuentros incestuosos, el padre Félix sube al púlpito y, según el relato

(...) tronó contra la murmuración y la calumnia de que eran víctimas los sacerdotes católicos, por parte de los liberales, raza de demonios que arderían eternamente en los infiernos; gritó, como energúmeno, contra la civilización actual, contra los teatros, contra esa prensa impía que con grandes caracteres estampaba en los periódicos, sin miramiento alguno a la divina jerarquía de que ellos se hallaban investidos (102).

En esta escena, Cardona pone en evidencia la máscara del sermoneador desdoblado. El cura ataca los valores culturales de la postura liberal, pero no muestra el rostro perverso de sus prácticas inmorales. La novela es una acusación directa a la iglesia y al mismo tiempo una defensa de la ética seglar.

El disgusto de los sectores afines a la religión católica se manifiesta en las distintas censuras que sufrió la novela. Quizá esta es la principal razón por la cual ha sido valorada negativamente y silenciada sistemáticamente por las editoriales y la crítica. En el caso de El primo, inmediatamente después de su primera edición en 1905, aparece una nueva publicación en Madrid, hecha por la Biblioteca Calleja en una colección titulada "La Novela de ahora". El éxito español de este texto produjo una edición de lujo que fue ilustrada por el pintor Manuel Picolo. Sin embargo, en el caso de La esfinge del sendero la situación fue distinta. Ya he señalado que luego de la fracasada edición bonaerense de 1916, hubo que esperar hasta 1970 para que finalmente en Costa Rica se "arriesgara" una segunda publicación.

\section{Consumición e institución}

Cuando La esfinge del Sendero se presenta al concurso conmemorativo del centenario de Argentina y propicia una polémica entre los integrantes del jurado, se despierta un interés, que aunque efímero, dejó varias huellas en la prensa bonaerense. Estanislao S. Zeballos fue uno de los defensores que intervino. En uno de los artículos apunta:

Considerando el concurso en el terreno estrictamente literario, esta obra tiene mérito, de gusto, de imaginación y de lenguaje, que imponía un primer premio, porque dicho carácter literario era obligatorio para el jurado. La obra es de una labor mental apreciabilísima en el terreno de las letras. La abonan la riqueza de su vocabulario, la fluidez de estilo, la intensidad de las descripciones, la verdad 
de los caracteres nítidamente dibujados. Su tema afecta, efectivamente, los puntos morales y religiosos que han influido en el tribunal, extraviando su juicio, según mi opinión, si no ha contribuido también a ello el carácter de extranjero del autor (Zeballos 1918: 404).

Ante las opiniones de este periodista, el jurado del Ateneo responde y plantea una extensa respuesta. La polémica incluyó la Revista de derecho, historia y letras, la revista Nosotros, y también el director de la revista Verbum terció en la discusión. Los puntos de la controversia fueron fundamentalmente de tipo ético.

Tampoco la crítica costarricense ha sido benévola con este autor. Abelardo Bonilla, quien fuera uno de los más connotados estudiosos de la literatura costarricense, expresó una opinión ambigua a propósito de Cardona. Mientras lo califica como el novelista de mayores capacidades en el género narrativo, considera que no representa lo nacional con el sabor y la profundidad con que lo hacen otros autores costarricenses (Bonilla 1967:143). Álvaro Quesada le cuestiona el que hubiera incursionado en la literatura cuando ya tenía una formación (¿o deformación?) literaria e ideológica definida. "Al igual que Gagini, sus prejuicios académicos no le permitieron captar la necesidad de la hibridez formal y lingüística para incorporar el discurso literario y la visión del mundo del realismo de García Monge" (Quesada 1986: 289). Lamentablemente, Quesada no explica cuáles son estos prejuicios ni cuáles son las magistralidades del realismo garciamongiano. Otros críticos que elaboran estudios sobre la literatura nacional, como es el caso de Virginia Sandoval de Fonseca, ni siquiera mencionan a Cardona.

Ya en 1979, el crítico Jorge Valdeperas advierte el olvido en el que la crítica ha tenido la obra de Jenaro. En este sentido apunta:

\footnotetext{
Es una de las figuras de nuestras letras menos estudiadas a lo largo de la historia y, sin embargo una de las más importantes para la comprensión de nuestra cultura y nuestra sociedad. Ignoramos las razones que han hecho posible el olvido en que ha estado sumido Cardona durante tantos años, pero no creemos que las mismas hayan sido precisamente inocentes (1979: 40).
}

A pesar de esta advertencia, en 1993 un riguroso estudio, elaborado por un equipo de investigadores costarricenses, titulado La Casa Paterna. Estructura y nación en Costa Rica, vuelve a dejar por fuera la obra cardoniana.

Una primera justificación de este olvido es el cuestionamiento de la codificación nacional. En Argentina, Estanislao S. Zeballos apuntaba que el carácter extranjero contribuyó al rechazo. Recuérdese que el primer lugar lo obtuvo el argentino Hugo Wast.

Un modo de observar las prácticas de poder que ejerce el sujeto nacional es mediante interpretación de los mecanismos de autoridad que formalizan el canon nacional de la literatura. La desnacionalización de un texto, apunta Rafael Rojas, es un primer mecanismo de olvido que va desde la franca exclusión hasta la elegante subvaloración de ciertas obras y autores (2000: 55). Pero en el caso de Cardona, el rechazo va más allá de los verosímiles autóctonos o, como apuntaba Harold Bloom, del establecimiento de un centro formador de canonización (En Rojas 2000: 53). Las ideas masónicas que sostienen el universo ideológico del proyecto cardoniano intentan quebrar el autoritarismo católico y, desde luego, las contradicciones morales que operan en el seno de la iglesia.

Aunque la novela, en medio de la polémica, no llegó aséptica a los lectores, de todos modos el programa ideológico de fondo facilitó la operación hermenéutica. De acuerdo con Wolfang Iser, esta operación se intensifica en la medida en que el texto 
renuncia a su intención (1987: 113). El proyecto anticlerical de Cardona es una posición fácil de identificar y, desde luego, esta renuncia no se produce. Según Iser, el sentido del texto comienza a perder su carácter estético y a tomar un carácter discursivo cuando se pregunta por su significado. "En ese momento cesa de significarse a sí mismo y con eso deja de ser un efecto estético" (1987: 125).

El lector de La esfinge del sendero queda entonces atrapado en la polarización anticlericalismo/catolicismo y el efecto más que estético, siguiendo a Iser, es de tipo discursivo.

Los aciertos estéticos de La Esfinge del sendero no fueron suficientes para ganarse un sitio en la historia de las producciones representativas de la literatura latinoamericana. Invocar el alma en pena de esta novela maldita implica asomarse a las argucias del poder en contra de las voluntades resistentes. Este no es el único texto descatalogado por razones extra-estéticas en la historia de nuestra literatura. Son muchas las esfinges silenciadas, a propósito, en los senderos del olvido.

\section{Notas}

1. El primer lugar lo obtuvo el argentino Hugo Wast, con la novela La casa de los cuervos.

2. Según el propio Alberto Cañas, no fue fácil conseguir el ejemplar de la novela. Finalmente, logró el apoyo de uno de los sobrinos de los Cardona, quien fue el que se encargó de facilitar el texto clandestinamente, a pesar de la oposición inicial de la familia (Entrevista a Alberto Cañas, 4 de marzo de 1997).

3. Según Monseñor Sanabria, la excomunión se aplicó a los lectores de la Biblioteca que tenía Julián Volio en San Ramón de Alajuela. La biblioteca había sido visitada por el Obispo Augusto Thiel, que amenazó con la excomunión, pero quien la ejecutó fue el cura del lugar (Sanabria 1982: 91).

\section{Bibliografía}

Bowden, George y Rafael Obregón Loría. 1940. La masonería en Costa Rica. Tercer período. San José: Imprenta Hermanos Trejos.

Bonilla Abelardo. 1967. Historia de la literatura costarricense. 2 ed. San José: Editorial Costa Rica.

Bourdieu, Pierre. 1995. Las reglas del arte. Génesis y estructura del campo literario. Trad. Tomas Kauf. Barcelona: Editorial Anagrama.

Cardona, Jenaro. 1916. La esfinge del sendero. Buenos Aires: Ed. Tragont. 2a Ed. 1970. San José: Editorial Costa Rica.

Foucault, Michel. 1999. Entre filosofía y literatura. Obras esenciales. Vol. I. Trad. Miguel Morey. Barcelona: Piados. 
Iser, Wolfgang. 1987. "La estructura apelativa de los textos" y "El acto de la lectura: consideraciones previas sobre una teoría del efecto estético". En Dietrich Rall (comp.). En busca del texto. México: UNAM.

Rojas, Rafael. 2000. Un banquete canónico. México: Fondo de Cultura Económico.

Quesada, Álvaro. 1986. La formación de la narrativa nacional costarricense (1890-1910). San José: Editorial Universidad de Costa Rica.

Sanabria Martínez, Víctor Manuel. 1982. Bernardo Augusto Thiel. Segundo Obispo de Costa Rica. Apuntes históricos. San José: Editorial Costa Rica.

Valdeperas, Jorge. 1979. Para una nueva interpretación de la literatura costarricense. San José: Editorial Costa Rica.

Zeballos, Estanislao S. 1918. “Triunfos de los costarricenses. Desidia literaria” En Atenea. II (5): 403-406. 